\title{
$\mathrm{As}_{2} \mathrm{~S}_{3}$ ガラスにおける組成均質度に及ぼす 熔融条件の影響
}

\author{
大 庭 茂樹・上 野 精一・長谷川 泰 \\ （科学技術庁, 無機材質研究所）
}

\section{Effect of the Melting Conditions on the Uniformity of Chemical Composition in the $\mathbf{A s}_{2} \mathbf{S}_{3}$ Glass}

\author{
By \\ Shigeki OOBA, Seiichi UENO and Yasushi HASEGAWA \\ (National Institute for Researches in Inorganic Materials)
}

\begin{abstract}
$\mathrm{As}_{2} \mathrm{~S}_{3}$ glass rods were prepared by melting the raw materials in evacuated silica glass ampoules which had been placed horizontally in a rocking furnace, and cooled at vertical position.

The effect of the melting temperature ranging $600 \sim 900^{\circ} \mathrm{C}$ on the uniformity of the chemical composition of the glass rod was studied. Maximum difference of the arsenic content at the each fraction of the glass rod, $\Delta_{A s}$, was employed as the evaluation of uniformity of the glass. To keep the $\Delta_{\mathrm{As}}$ value less than $0.5 \mathrm{wt} \%$, melting time of $24 \mathrm{~h}$ was required for melting at $600^{\circ} \mathrm{C}, 6 \mathrm{~h}$ at $700^{\circ} \mathrm{C}$, and $1 \mathrm{~h}$ at $800^{\circ} \mathrm{C}$. While only by heating up to $900^{\circ} \mathrm{C}$, the $\Delta_{\mathrm{As}}$ value went down to $0.3 \mathrm{wt} \%$ and less.

For the sample with poor uniformity, it was found that the arsenic contents in a lower half of glass rod $(63 \sim 64 \mathrm{wt} \%)$ was higher than the average arsenic content $(60.9 \mathrm{wt} \%)$.
\end{abstract}

[Received December 19, 1974]

\section{1. 緒言}

カルコゲン化物ガラスは 1950 年代から急速に研究さ れ始めた非酸化物ガラスで, 多岐にわたる膨大な数の報 文が現在までに公表され，多くの知見が得られている. しかしながら基本的事項については不明な点が多い。た とえば基本的な As-S 系ガラスを例にとっても, 実験的 な規模で作製されたガラス試料について，各部分におけ る化学成分の濃度差がどの程度か, またそれらが熔融条 件などとどのような関係にあるかについての情報は少な W.

G.A. Nikandrova ${ }^{1)}$ のミクロ的な不均一性についての 研究は組成領域との関連を扱ったものであり，A. Vaš$\mathrm{ko}^{2)}$, A.R. Hilton ${ }^{3)}$ の報告は光学材料的見地からガラ スの均質度について触れている. 筆者らはカルコゲン化 物ガラスに関する基礎研究の一環として, $\mathrm{As}_{2} \mathrm{~S}_{3}$ ガラス の試料作製時における均質なガラス形成が少なくとも, $500^{\circ} \mathrm{C}, 24$ 時間以上の加熱熔融を必要とすることを報告 しだ).

本報告は $\mathrm{As}_{2} \mathrm{~S}_{3}$ ガラス試料各部分の 組成を化学分析 することにより, 試料作製時における熔融条件（熔融温
度と熔融時間）のガラス均質度に及ぼす影響をまとめた ものである.

\section{2. 実 驗 方 法}

\section{1 試料作製}

$\mathrm{As}_{2} \mathrm{~S}_{3}$ ガラスの原料は純度がそれぞれ $99.9999 \%$ の砒 素と, $99.999 \%$ の硫黄を用いた. 砒素は $5 \mathrm{~mm}$ 以下 の, 硫黄は 5 1 mm の小粒塊状で, ガラス化時の重量 が $15 \mathrm{~g}$ になるよう所要重量を秤量し, 内径 $10 \mathrm{~mm}$, 熔 封時の長さが約 $100 \mathrm{~mm}$ の透明シリカガラスアンプル内 に硫黄を下部に, その上部に砒素を装入し, $10^{-5}$ Torr の 減圧下で熔封した. 高純度砒素の粉确, 秤量, アンプル への装入は窒素雾囲気中で行った. そしてアンプル内で の原料間の再現性のある混合は極めて難しいために, 混 合度合の相違によるガラス均質度への影響を 避けるた め, アンプルに装入された砒素と硫黄の混合はあえて行 わなかった. 熔融は水平状態でアンプルの中点を中心 に, 上下に約 10 度, 周期毎分 1 回の割合で摇動する均 熱部分が約 $200 \mathrm{~mm}$, 長さ $500 \mathrm{~mm}$ の管状電気炉に上記 アンプルを装着し，つぎに述べるようなスケジュールで 
熔封加熱，冷却を行った。

常温から 2 時間で $400^{\circ} \mathrm{C}$ まで昇温し，そのまま 2 時 間予備加熱する.この操作は原料間の急激な反応を防ぐ ために行った.すなわち, 直線的に急激な昇温を行うと 原料間の反応で，ほぼ $35 \mathrm{kcal} / \mathrm{mol}$ の発熱を生じ，アン プルが破壞される恐れがある.つぎに $400^{\circ} \mathrm{C}$ から， 600 ${ }^{\circ} \mathrm{C}, 700^{\circ} \mathrm{C}, 800^{\circ} \mathrm{C}$ および $900^{\circ} \mathrm{C}$ の各温度まで 2 時間で 昇温し, 各温度でそれぞれ $0,1,2,3,4,5,6,24$ 時間加 熱熔融した。これらの熔融条件, すなわち $600^{\circ} \mathrm{C} \sim 900^{\circ} \mathrm{C}$ の各温度と, 各温度における保持時間のガラス均質度に 及ぼす影響を，ガラス試料各部分の化学分析ならびに密 度の測定により調べた。加熱時間がへ時間の場合とは, 所定温度に昇温した状態で, 電気炉の摇動を止め, 炉体 を水平から垂直状態に固定することにより，炉内のアン プルを直立させ，直ちに冷却過程に移したことを示す． 加熱時間が 1 時間の場合とは, 所定温度で 1 時間保持し た後，アンプルを直立させてから，泠却過程に移したこ とを示す．なおアンプルが水平におかれた場合と垂直に 立てられた場合を比較するため, $600^{\circ} \mathrm{C}$ と $700^{\circ} \mathrm{C}$ でそ れぞれ 1 時間加熱した場合の試料について，別個にアン プルを直立させないで，水平状態のままで冷却した試料 を作製した。

融液から冷却する場合に $\mathrm{As}_{2} \mathrm{~S}_{3}$ が結晶し難いことは W.P.A. Jonker $ら^{5)}$ や S.S. Flaschen $ら^{6)}$ により良く 知られているが， $\mathrm{As}_{2} \mathrm{~S}_{3}$ ガラスを水熱条件下で結晶化さ せた例 ${ }^{7)}$ はある。一般的な冷却条件下では $\mathrm{As}_{2} \mathrm{~S}_{3}$ の結 晶は生じない。このような事情から冷却は電気炉の放冷 によった。転移温度近くまでの冷却速度は約 $4^{\circ} \mathrm{C} /$ 分であ る. $\mathrm{As}_{2} \mathrm{~S}_{3}$ ガラスの転移温度 $\left(180^{\circ} \mathrm{C}\right)$ 付近の 冷却速度 は，実用酸化物ガラスの徐冷にならい ${ }^{8)}, 1^{\circ} \mathrm{C} /$ 分とした。 その結果泠却固化後, アンプルから取り出した直径約 $10 \mathrm{~mm}$, 長さ約 $60 \mathrm{~mm}$ の $\mathrm{As}_{2} \mathrm{~S}_{3}$ ガラス試料は切断, 研 磨加工に際し，破損を生じることはなかった。

棒状試料は冷却時の状態で底部 $7 \mathrm{~mm}$ を除いて, $5 \mathrm{~mm}$ 間隔で切断し底部から上部に対して，順次 No. 1〜11 ま での番号をつけ, 測定結果の表示をわかり易くした. (図-2 参照)

\section{2 密度測定}

作製条件による試料ガラス各部分の組成変化と密度と の関係を知るため，蒸溜水を用いたアルキメデス法によ り室温 $\left(25^{\circ} \mathrm{C} \pm 1^{\circ} \mathrm{C}\right)$ で試料ガラスの密度測定を行った. 精度は $\pm 0.003 \mathrm{~g} / \mathrm{cm}^{3}$ である. また比較のため充分な徐 冷を行った砒素含有量が 29.2〜66.2 wt\% の As-S 系 ガラス 7 種類の密度も併せて測定し, それらの結果をま とめて 図-1 に示した。なお M. Tanaka ら ${ }^{9)}$ と R.L. Myuller ${ }^{10)}$ による報告の結果も参考にした.

図-1 中に示す $\mathrm{As}_{2} \mathrm{~S}_{3}$ 結晶の密度は水熱合成したもの ${ }^{7}$ と天然産のもの ${ }^{11)}$ について，安た $\mathrm{As}_{4} \mathrm{~S}_{4}$ 結晶は天然産

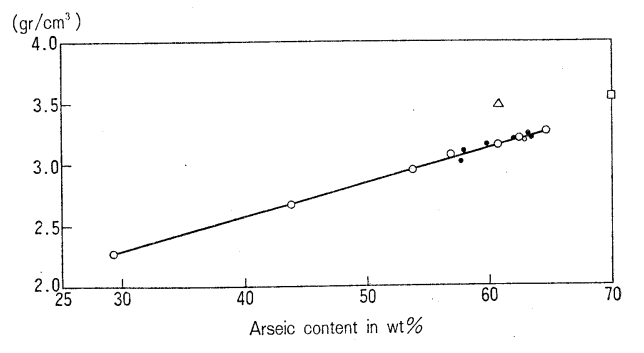

- : each fraction of $\mathrm{As}_{2} \mathrm{~S}_{3}$ glass molten at $600^{\circ} \mathrm{C}$ for $1 \mathrm{~h}$. $O$ : uniform glass

$\square:$ Realgar $\left(\alpha-\mathrm{As}_{4} \mathrm{~S}_{4}\right)$

$\triangle$ : orpiment $\left(\mathrm{As}_{2} \mathrm{~S}_{3}\right)$

Fig. 1. Density of $\mathrm{As}_{2} \mathrm{~S}_{3}$ glass.

のもの ${ }^{11)}$ にぷいての值である.

\section{3 化学分析}

切断して番号をつけた直径 $10 \mathrm{~mm}$ の円板試料を更に 上下面を含む $3 \times 3 \times 5 \mathrm{~mm}$ （重量約 $100 \mathrm{mg}$ ）の大きさ に切断し, 硫黄と砒素の組成をつぎに述べる化学定量分 析法で求めた.

試料を水酸化ナトリウム溶液と過酸化水素水の混合液 に溶解した後で, 硫黄は硫酸バリウムとして重量分析 で，砒素は砒酸銀の沈澱をつくり，銀をVolhard 法で 滴定によりそれぞれ求めた ${ }^{12)}$.

分析結果による As+S の含量は 99.9〜100.3\% であ った，以下述べるガラス組成は砒素含有量で示した。

\section{3. 結 果 と考 察}

それぞれの熔融条件で得られた棒状ガラス試料の各部 分における組成の分布を、図-2a)〜d) に示した. 、ずれ も縦軸にガラス試料位置を, 横軸に砒素の重量百分率を とり, 加熱温度別に a) d), 加熱時間をパラメーター にとって示した. また各試料ガラスにおける砒素分析值 の最大值と最小值の差 $\left(\Delta_{\mathrm{As}}\right)$ を表-1 に示した.

Table 1. Maximum difference value of arsenic constent $\left(A_{\mathrm{As}}\right.$ in $\left.\mathrm{wt} \%\right)$ in the $\mathrm{As}_{2} \mathrm{~S}_{3}$ glass prepared by different melting conditions.

\begin{tabular}{lcccccc}
\hline $\begin{array}{c}\text { Melting } \\
\text { temperature } \\
{ }^{\circ} \mathrm{C}\end{array}$ & \multicolumn{6}{c}{ Holding time in $\mathrm{h}$} \\
\cline { 2 - 7 } & \multicolumn{1}{c}{0} & 1 & 2 & 3 & 6 & 24 \\
\hline 600 & 12.2 & 5.7 & 4.2 & 3.7 & 2.4 & 0.5 \\
700 & 7.9 & 3.3 & 2.6 & 1.6 & 0.6 & 0.3 \\
800 & 4.4 & 0.5 & 0.2 & 0.1 & & \\
900 & 0.3 & 0.1 & & & & \\
\hline
\end{tabular}

図-3に摇動を止めた後アンプルを水平状態（僅かに 傾けた状態）で泠却させて得た試料ガラスの断面図と， 各位置における砒素含有量の分析值を記入して示した. 図-3 a) は $600^{\circ} \mathrm{C}, 1$ 時間, 図 $-3 \mathrm{~b}$ ) は $700^{\circ} \mathrm{C}, 1$ 時間摇 動しながら加熱した試料である.

図-3 a）の点線で区切られた下層部分はアンプルより 取り出した際, 上部と分離した明らかに色の異なるガラ 


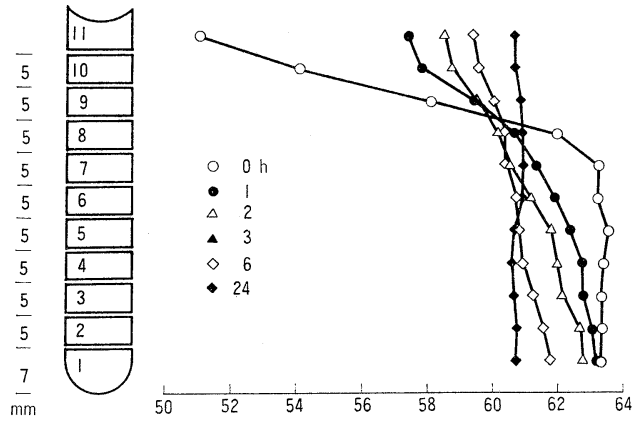

(a) $600^{\circ} \mathrm{C}$

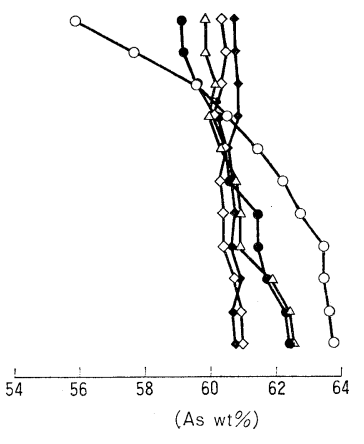

(b) $700^{\circ} \mathrm{C}$

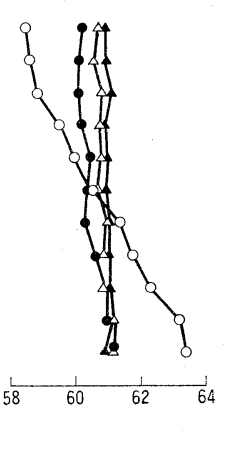

(c) $800^{\circ} \mathrm{C}$

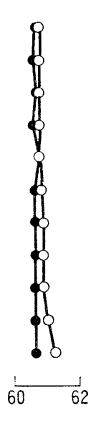

(d) $900^{\circ} \mathrm{C}$

Fig. 2. Effect of holding time on the arsenic content vs. fraction of the sample at different temperature.

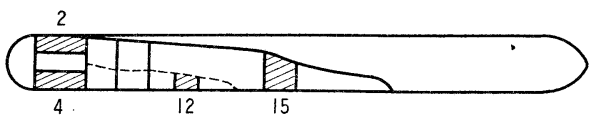

(a) $V-1-6\left(600^{\circ} \mathrm{C} \mathrm{Ih}\right)$

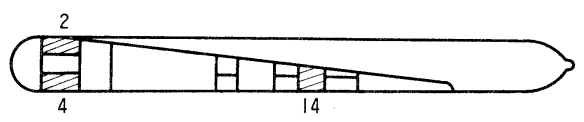

(b) $V-1-7\left(700^{\circ} \mathrm{C} / \mathrm{h}\right)$

(a)

$\begin{array}{ll}\text { V-1-6-2 } & 59.77 \\ \text { V-1-6-4 } & 63.42 \\ \text { V-1-6-12 } & 62.23 \\ \text { V-1-6-15 } & 57.68\end{array}$

(b)

$\mathrm{V}-1-7-2$

As $(w t \%)$

$\mathrm{V}-1-7-4$

60.29

62.76

60.39

Fig. 3. Sketch of the glass sample cooled at horizontal position.

ス部分であった。

これらの結果をまとめるとつぎの通りである.

1）高純度の砒素と硫黄をシリカガラスアンプルに封入 し, 摇動電気炉内で一定時間加熱熔融し，原料間の反応 や融液の均質化をはかった後に，融液をアンプル内で冷 却固化させて得られた棒状の $\mathrm{As}_{2} \mathrm{~S}_{3}$ ガ ラ ス試料各部分 の組成の均質度は，熔融温度と熔融時間に顕著に影響さ れた。実験範囲内では，加熱温度が $900^{\circ} \mathrm{C}$ の場合最高 に良く，単に $900^{\circ} \mathrm{C}$ まで昇温させるだけで，吪素の各 部分における差は $0.3 \%$ 以下になっていた，均質度最 低は $600^{\circ} \mathrm{C}$ に昇温させて，すぐ冷却に移った熔融時間 0 時間の場合で，砒素の差は $12.2 \%$ であった．熔融温 度が $600^{\circ} \mathrm{C}$ の場合でも 24 時間加熱すると各部分の砒素 の差は $0.5 \%$ になる。これと同等の均質質度を得るた めには，熔融温度が $700^{\circ} \mathrm{C}$ の場合で 6 時間, $800^{\circ} \mathrm{C}$ の場 合 1 時間でよかった。

2）予熱段階ともいえる $400^{\circ} \mathrm{C} ， 2$ 時間の加熱過程から 2 時間で各々の所定温度に昇温させた場合の均質度への 影響は各熔融温度における熔融時間 0 時間の場合におけ
る試料各部分の砒素の差から明瞭に示され， $600^{\circ} \mathrm{C}, 700$ ${ }^{\circ} \mathrm{C}, 800^{\circ} \mathrm{C}$ の順に高温になる程，均質度は良くなり， $900^{\circ} \mathrm{C}$ になると飛躍的に良くなる. $800^{\circ} \mathrm{C}$ から $900^{\circ} \mathrm{C}$ の 間で砒素の差 $\left(\Delta_{\mathrm{As}}\right)$ は 10 分の 1 以下になり, この温 度領域で $\mathrm{As}_{2} \mathrm{~S}_{3}$ 融液の均質性に寄与する因子（例えば 粘度）に大きな変化のあることが推定された。

3） $800^{\circ} \mathrm{C}$ 以下の熔融時間の比較的短かい場合の試料で は，下部における砒素が程度の差こそあれ，上半部より 多く，その量は 63〜64 wt％の領域であった。

図-3 に示したようにアンプルを水平状態のままで, 冷却固化させた場合にも下層部分の砒素含有量は上記領 域にあるので，アンプルを直立させた場合，砒素の多い 部分は密度が大きく，アンプル下部に移動すると思われ た.したがって熔融条件の不充分なガラス棒状試料は, 冷却固化させた時の上下位置により組成差を生じた。す なわち下の部分は砒素が多い。

\section{4. 総 括}

$\mathrm{As}_{2} \mathrm{~S}_{3}$ ガラス原料をシリカガラスアンプル内で熔封し て, 摇動電気炉内で熔融し, 組成の均一化をはかる場合 における熔融温度と時間の影響は著しい. $400^{\circ} \mathrm{C}$ で 2 時 間予備熔融をした後に，2 時間で $600 \sim 800^{\circ} \mathrm{C}$ に昇温し， 熔融することにより得られる棒状ガラス試料各部分にお ける䂣素の含有量差を $0.5 \%$ 以下にするためには，600 ${ }^{\circ} \mathrm{C}$ で 24 時閒, $700^{\circ} \mathrm{C}$ で 6 時間， $800^{\circ} \mathrm{C}$ で 1 時間加熱 熔融する必要がある. 熔融が不充分の場合, 棒状試料下 半部の砒素含有量が $63 \sim 64 \%$ になる.

また $900^{\circ} \mathrm{C}$ に昇温するだけで組成均質度が飛躍的に良 くなることから, $800^{\circ} \mathrm{C}$ から $900^{\circ} \mathrm{C}$ の間に組成均質度 に及ぼす因子に大きな変化のあることが推測された．

終りに本報告で言及できなかったシリカガラスアンプ ルの寸法, さらには電気炉の摇動周期などの影響につい て研究中であることを付記する。 
謝辞 本研究を実施するにあたり，研究の端緒を与えられ るとともに研究遂行に適切なる助言と激励をたまわった無機材 質研究所山内前所長なら びに田賀井所長に深甚なる感謝の意を 表します。

$$
\text { 文献 }
$$

1) G.A. Nikandrova and G.M. Orlova, J. Appl. USSR 44, 1897-99 (1971).

2) A. Vaško, "Optical Properties of Amorphous and Liquid Selenium in” W. Charles(ed.), "The physics of selenium and tellurium” Pergamon Press, Oxford (1969). p. 241-54.

3) A.R. Hilton, J. Non-Crystalline Solids 2, 28-39 (1970).

4) S. Ueno, S. Ooba, and Y. Hasegawa, Tenth Intern. Congress on Glass, July 1974, Kyoto. Report No. 13, p. 74-78.

5) W.P.A. Jonker, Z. anorg. Chemie 62, 89-107 (1909).
6) S.S. Flaschen et al, J. Am. Ceram. Soc. 43, 27478 (1960).

7) Y. Fujiki and Y. Hasegawa, Mineral. J. 7, 542 (1975).

8) E.B. Shand, "Glass Engineering Handbook", 2 nd ed. McGraw Hill Book Co., New York (1958). p. 106-09. See Table 4-1.

9) M. Tanaka and T. Minami, J. Appl. Phys. 4, 939 (1965).

10) R.L. Myuller et al, "Investigation of the Electric Conductivity of the Arsenic-Sulfur System in the Vitrious State" in R.L. Myuller, "Solid State Chemistry”, Consultant Bureau, New York (1966). p. 168-79.

11) C. Palache and C. Frondel (ed.), "The System of Mineralogy" 7th ed. Vol. 1 (1963) John Wiley and Sons, Iríc., New York. p. $257\left(\mathrm{As}_{4} \mathrm{~S}_{4}\right)$ and p. 267 $\left(\mathrm{As}_{2} \mathrm{~S}_{3}\right)$.

12）大庭茂樹, 上野精一, 分析化学, 21, 1084-87 (1972). (12/19/1974 受付)

Note $\cdot$ ノート

\title{
Heats of Immersion of $\mathrm{Na}_{2} \mathrm{O}-\mathrm{B}_{2} \mathrm{O}_{3}$ Glasses in n-Butylamine-Cyclohexane Solution
}

\author{
By \\ Makoto HATTORI \\ (Department of Applied Chemistry, Faculty of Engineering, Hiroshima University)
}

\begin{abstract}
$\mathrm{Na}_{2} \mathrm{O}-\mathrm{B}_{2} \mathrm{O}_{3}$ ガラスの $n$-ブチルアミン-シクロヘキサン溶液への浸漬熱
\end{abstract}

\author{
服 部 信 \\ (広島大学 工学部 応用化学科)
}

It is well known that some physical properties of alkali borate glasses, such as thermal expansion and viscosity, show a peculiar dependence on the content of alkali oxide. This anomaly, which is known as "boric oxide anomaly", has been explained by many authors in terms of the change of the co-ordination number of boron atom to oxygen atoms. $\mathrm{B}_{2} \mathrm{O}_{3}$ glass is considered to be mainly composed of triangular $\mathrm{BO}_{3}$ groups which share their oxygen vertices to give a disordered three-dimensional network. When alkali oxide is added to $\mathrm{B}_{2} \mathrm{O}_{3}$ glass, some of the three-co-ordinated borons $(3 \mathrm{~B})$, or $\mathrm{BO}_{3}$ groups, are converted to four-coordinated borons $(4 \mathrm{~B})$, or tetrahedral $\mathrm{BO}_{4}$ groups.

In a $\mathrm{BO}_{3}$ unit, where the trivalency of boron results from the $\mathrm{sp}^{2}$ hydridization, one vacant $\mathrm{p}$ - orbital is left on boron atom. Thus the boron atoms in $\mathrm{BO}_{3}$ groups on the glass surface are expected to act as acid sites to electron-pair donors. In $\mathrm{BO}_{4}$ units the oxygen atoms are bonded by tetrahedrally directed bonds which result from the $\mathrm{sp}^{3}$ hybridization. Thus no vacant $\mathrm{p}$-orbital is left on each boron atom in $\mathrm{BO}_{4}$ groups. The purpose of the present work is to study the contribution of acid-base interaction to the heat of immersion of borate glasses in organic base.

$\mathrm{Na}_{2} \mathrm{O}-\mathrm{B}_{2} \mathrm{O}_{3}$ glasses were prepared from $\mathrm{Na}_{2} \mathrm{CO}_{3}$ and $\mathrm{H}_{3} \mathrm{BO}_{3}$. The organic base used was $n$-butylamine, which was of reagent grade and was purified by distillation before use. The specific surface area of glass sample was determined by BET method. Heat of immersion, $H_{i}$, was measured with a twin- 